\title{
Yearly Heat Loss Analysis of a Heat Recovery Ventilator Unit for a Single-Family House in St. John's, NL, Canada
}

\author{
Rabbani Rasha, and M. Tariq Iqbal
}

\begin{abstract}
This paper represents an energy consumption and heat loss analysis of a heat recovery ventilator unit in a single-family detached house in St. John's, NL, Canada. An energy-efficient house is a growing attraction to control the air infiltration, provide a comfortable environment with reduced yearly electricity cost. A mechanical induced ventilation system is inevitable to increase energy efficiency and to reduce greenhouse gas emissions of the house in order to supply fresh air. A heat recovery ventilator (HRV) is an air to air heat exchangers that recovers heat from inside of the house and delivers this preheated and fresh air to the space for maintaining the occupant's comfort. In this paper, yearly energy consumption with the heat loss of a typical heat recovery ventilator unit is presented. MATLAB, $B E$ opt, and Microsoft Excel are used to do all necessary simulation with calculation using one-year logged data. Methodology, results with graphs and detailed analysis of this research are included in this paper. This research indicates that the cost of running a HRV for a year in a house in St. John's could be as high as $\$ 484$ per year with an unknown air quality improvement.
\end{abstract}

Index Terms - heat recovery ventilator, comfortable environment, energy consumption, and loss analysis.

\section{INTRODUCTION}

Energy requirements for space heating have increased and most of the space heating source is fossil fuel based. So, the researchers have focused on finding alternative energy source as well as the best practice of using energy efficiently. One of the possible and successful options is to improve the existing energy systems integrated with heat recovery ventilation (HRV), also recognized as mechanical ventilation heat recovery (MVHR). A typical heat recovery unit can extract about (60 -95) \% of residual heat and contribute to increasing the energy efficiency of the buildings [1]. This unit has been used not only in the residential sector but also in the industry since last two decades, as the total $26 \%$ of industrial energy is still wasted as hot gas or fluid in many countries of the world [2]. In terms of industrial use, this system is normally called waste heat recovery unit due to the huge amount of air exchange between two sources at various temperatures. The earliest study of mechanical ventilation system with heat recovery unit of building has been done in Denmark and the result showed that mechanical ventilation with heat pump recovery is useful in terms of reduction in dust mite populations in mattresses and carpets [1]. Nazoroff et al. [3] studied the mechanical ventilation system with a counter-flow heat recovery unit to find out the effectiveness of this type of system, using energy-efficient control technique. They demonstrated that this kind of system might satisfy the energy conservation goal and able to meet the indoor air quality of the house by following the strategy of building tight houses at an affordable cost. Apart from the advantages, this system has a major disadvantage because it consumes a large amount of electrical power as an input that's why in some cases, it mentioned that household's electricity consumption is increased. To resolve and recover the energy loss, researchers have emphasized to build a system that can integrate with heat recovery unit [4]. Nguyen et al. [5] have studied the overall performance of mechanical ventilation heat pump system with heat recovery by using forced ventilation. They used four types of different system to recover the sensible heat during ventilation process and the systems are no heat recovery, separate sensible heat recovery, single heat recovery as integration of heating ventilation, and double heat recovery with heat pump. Their result concluded that the most efficient and energy-saving system was integrated mechanical double heat recovery system for maintaining the air quality of indoor space. An advanced mechanical ventilation heat recovery (MVHR) unit with the help of heat pump was developed by Riffat and Gillott [6] . Their findings showed that this type of system is less expensive with less maintenance and air change per hour $(\mathrm{ACH})$ compiled with the ASHRAE standards to provide fresh and quality indoor air. Manz et al. [7] did both the experiment and numerical simulations in order to evaluate the performance for single-room ventilation unit with regenerative mechanical ventilation heat recovery. The result reported that it is possible to obtain the temperature efficiencies up to $78 \%$ at lower electrical energy input. Also, this unit can exchange the inside and outside air efficiently at the highest comfort level. In cold climate country or arctic region where the seasonal difference is more, it is not easy to maintain and balance of indoor air quality by using traditional heat recovery unit because of the continuous moisture problems and the tendency of outside air drops below the freezing point. To mitigating this issue, extensive research has been going on worldwide. Kragh et al. [8] have made an innovative mechanical ventilation heat recovery system. It is determined that this type of system can defrost itself without taking additional input energy in cold or arctic climates with high heat recovery efficiency and accomplished to defrost below the freezing point. The temperature efficiency at freezing condition and the overall system efficiency was about $88 \%$ and $85 \%$ respectively. Cuce and Riffat [9] did experimental, theoretical, simulation analysis with thermodynamic performance assessment of heat recovery systems. They also discussed the way of integrating this unit with mechanical ventilation system and the running cost of the fans of this unit to overcome the pressure loss of it. It indicated that this unit can diminish the 
energy consumption for heating, cooling, and ventilation in order to make the energy-efficient house. Lu et al. [10] demonstrated a crossflow, plastic film type heat recovery unit to attain the optimal performance of it. The research ended with few conclusions like pressure drop increases with air flow rate and decreases with film thickness, film vibration enhances the heat transfer rate of this system, and the effectiveness of this type of heat exchanger varies from 0.65 to 0.85 with increasing the airflow rate. However, maintaining higher air quality in the house causes increasing ventilation loss. That is why researchers have been trying to develop new design of heat recovery ventilation system. Hviid and Svendsen [11] have constructed a state-of-the-art passive ventilation system with heat recovery unit and cooling for temperature changes. The result presented that the pressure drops, and heat transfer efficiency was about $0.37 \mathrm{~Pa}$ and $75.6 \%$ respectively for the respective air flow rate $560 \mathrm{l} / \mathrm{s}$. Persily et al. [12] discussed an air to air heat exchanger to acquire the recovery efficiency of a typical house, equipped with heat recovery ventilator unit. The recovery efficiency relied on the fan speed of an HRV and it mentioned around (50-60) \% of heat recovery efficiency without taking the losses in fan power as well as the heat conduction through the metal case of the heat exchanger. It is likely to save the energy to reduce the mismatch between energy and demand as well as to put less pressure on using conventional energy. Research revealed that it is possible to save energy from HVAC system, using the heat recovery unit. Ke and Yanming [13] focused a study on estimating the applicability of heat recovery ventilator employing various sites in China. This study exposed that double heat exchanger instead of single heat exchanger ventilation system should be able to adapt the requirement of energy recovering through ventilation system in the climate as mentioned above zones. Cost and payback analysis of this type of system are important for making this system more affordable and familiar to people. The overall cost of this heat recovery system completely relies on the technology that they have. The payback period normally varies from a couple of years to 15 years, and their lifespan is mostly greater than 30 years [1]. Among the numerous heat recovery technologies, mechanical ventilation with heat recovery is more efficient in terms of cost and the amount of recovered energy. Tommerup and Svendsen [14] mentioned that mechanical ventilation with heat recovery can be installed for approximately $30 \mathrm{Euro} / \mathrm{m}^{2}$ however, from the literature search it was found that the operational cost of air to air heat recovery system is quite high due to the running electrical cost of fans of this system.

From the literature search, it is found that heat recovery unit with mechanical ventilation plays an essential role in order to make energy efficient with low energy consumed. This system can contribute significantly to reduce the heating demand of the house, as the waste heat or exhaust heat of occupied space is used to preheat the incoming air for enhancing thermal comfort. Most of the researchers have performed and did a cost analysis of different types of mechanical ventilation heat recovery system. In our research, we discussed the energy consumption and heat loss scheme of a heat recovery unit in a house for 12 months' period. No such study has been done for Newfoundland,
Canada.

In this research, section 2 will present the HRV components and operation, section 3 will describe the methodology and experimental setup. Calculation method, simulation results with discussion will be discussed respectively, and the paper will end with a conclusion.

\section{HRV COMPONENTS AND OPERATION}

Heat recovery ventilation (HRV) is an energy-efficient appliance and plays a significant role to maintain the indoor air quality of the house. It also contributes to making an energy-efficient house by incorporating the HVAC system. This system provides cost-effective and environmentally friendly energy to mitigate energy consumption and the operating cost of the building [15]. This type of system consists of fans, filters, airtight insulated casing, heat exchanger or core, drain, sensors with controllers, and inlets and exhaust passage. The air streams can flow in cross flow or counter flow directions. In our research, a crossflow type HRV was used that is showed by figure (1). The working principle of this system is simple as stale air from indoor passes through the core and exchange the heat with fresh air that comes from outside. After taking the heat, the incoming air gets heated and then this preheated fresh air directly goes to the indoor space to provide the excellent quality air in order to continue the highest level of thermal comfort for the occupants. Finally, the exhaust air goes outside by releasing its heat. Thus, a heat recovery unit works efficiently to exchange the indoor and outdoor air. When heat is transferred from the exhaust to the outdoor air stream during the heating season, condensation can form inside the heat exchange core. For this reason, drain pans are located inside the HRV to collect any water buildup, and the HRV is connected to a sanitary drain [16].

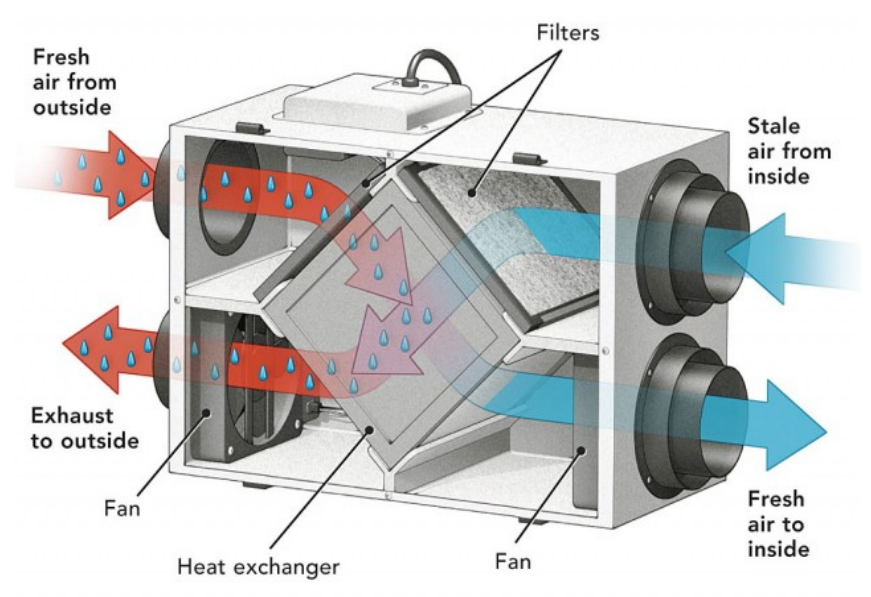

Fig. 1. A typical heat recovery unit [17]

\section{Experimental Set Up With Methodology}

Our selected house was in St. John's, NL, Canada with latitude $\left(47.56{ }^{\circ} \mathrm{N}\right)$ and longitude $\left(52.71{ }^{\circ} \mathrm{W}\right)$. A heat recovery ventilator (HRV) was installed there. The model of the HRV was VENMAR AVS CONSTRUCTO 1.5 with dimensions (height: $419 \mathrm{~mm}$, width: $768 \mathrm{~mm}$, depth: $438 \mathrm{~mm}$ ). The main objective of it is to provide comfortable, healthy fresh air for the building's occupants. However, the problem is the heat loss of it. So, we built an experimental set up that is showed by the figure (2), with the help of HRV, data logger, computer and so on to find out the 
amount of yearly heat loss through HRV. The working principle of this set up is modest like during the winter the inlet air fan takes the outside air and in the same time the exhaust air from room exchange heat with this incoming air to make preheated and fresh air for the room. After that, this incoming air goes directly to room and the exhaust air directly goes into environment by releasing the heat. The temperature sensor LM 35 sense both the temperature of incoming air and exhaust air. The temperature data are amplified with the amplifier that has gain 13.42. Then the amplified data are logged by the national instrument data logger (Model: USB 1208LS). Finally, these logged data were displayed in the Laptop, running with MATLAB code. The block diagram of this operation procedure is shown in figure (3). rate. These equations are as follows,

Heat loss through, $H R V=Q_{v} * d * C_{p} * \Delta T$

Where, flow rate, $Q_{v}=A * V=3.1416 *(0.0762)^{2} * 2.75$

$=0.0501 \mathrm{~m}^{3} / \mathrm{s}$

Density of air, $d=1.293 \mathrm{Kg} / \mathrm{m}^{3}$

Specific heat of air, $C_{p}=1005 \mathrm{~J} / \mathrm{Kg} . \mathrm{K}$

$\Delta T=$ Temperature difference of inlet and exhaust air of HRV

After putting all values in equation (1), we calculated the heat loss of the heat recovery ventilator per minutes. We took 44640 data for January, March, May, October, and December. Also, we took 43200 data for April, September, November and 40320 for February. It is evident that we turned off the HRV for June, July, and August so for these three months the heat loss through HRV is equivalent to

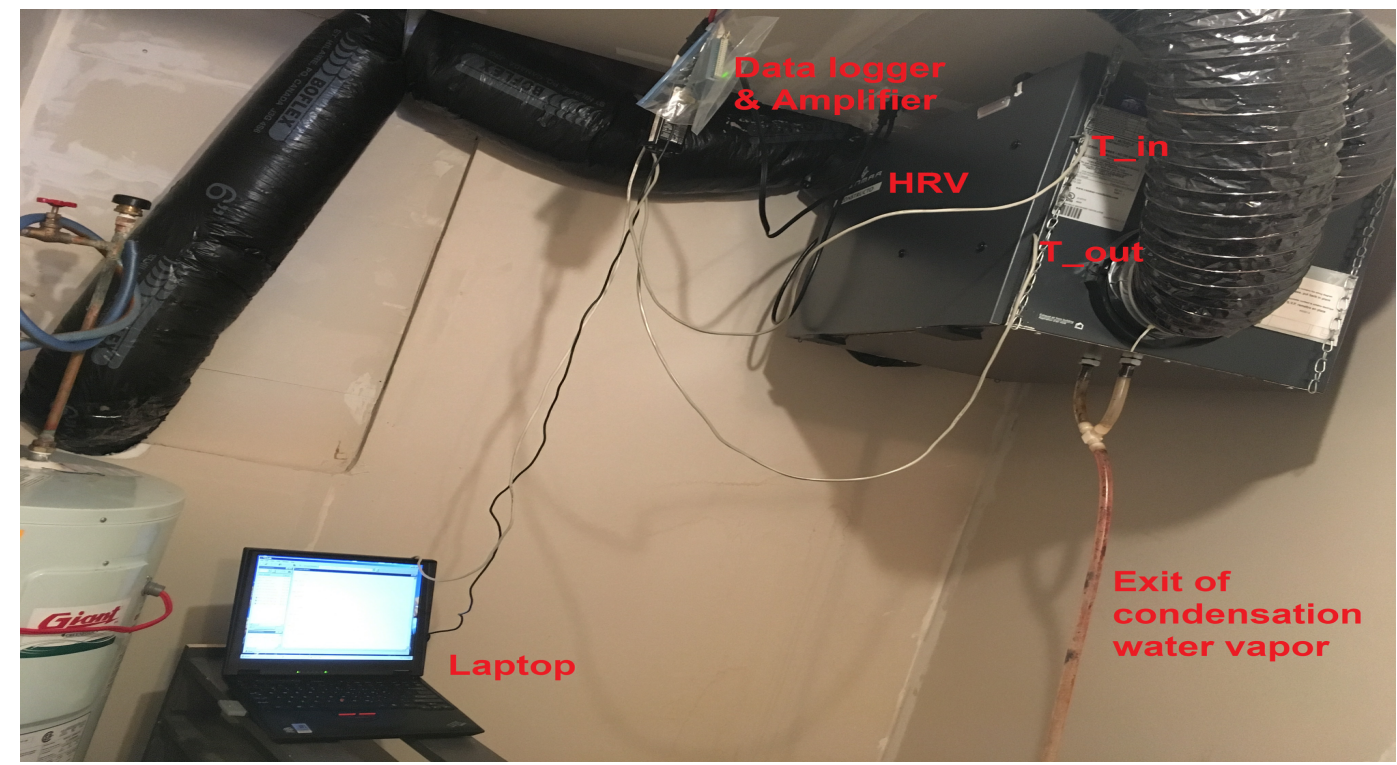

Fig. 2. Experiment set up of HRV

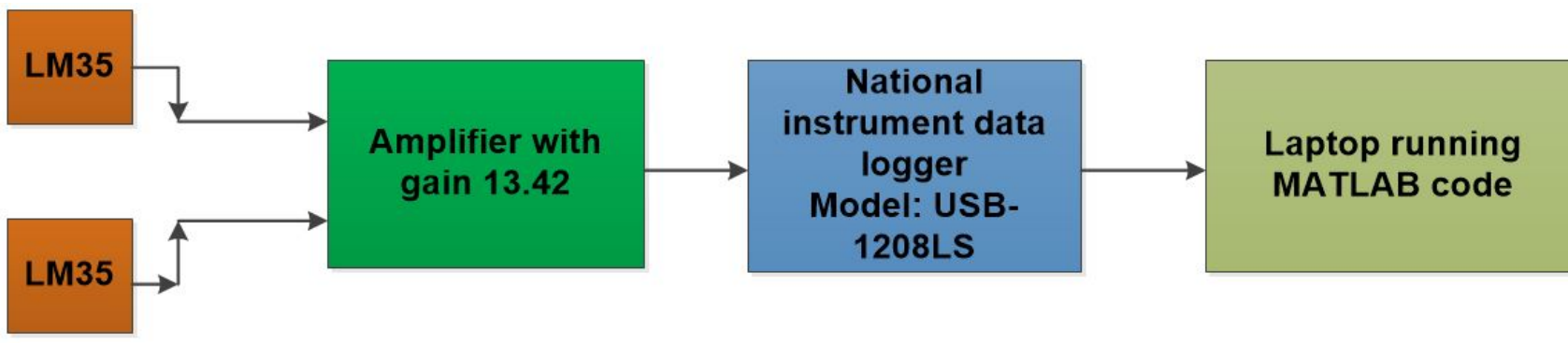

Fig. 3. Block diagram of the experiment procedure

\section{Calculation Method}

To calculate the heat loss through heat recovery ventilator, we logged the monthly inlet and outlet temperature difference data by using MATLAB. We set up the data logger like a way that can log data per minute. So, it can $\log$ about 525600 data in one year. The diameter of inlet and outlet air duct connected to HRV is 0.1524 meter. We also measured the air velocity through the duct using anemometer and got around $2.75 \mathrm{~m} / \mathrm{s}$.These parameters were used to calculate the flow rate through the duct. We used several equations to get heat loss as well as the flow zero. All the necessary graphs are shown in the result and discussion section. Here, the heat recovery ventilator also consumes electricity over the year to run its motor.

The electricity consumption of the HRV is calculated using equation (2),

Electrical energy consumption=Power*24*273

Here, power of the HRV is measured using the Kill a Watt device. Kill a Watt is an electrical device that can be used to measure volt, current, power, and frequency of any electrical equipment's. Our measured power of the HRV is 110 Watt. After putting this value in equation (2), the total electricity 
consumption of the HRV is $720 \mathrm{kWh}$ excluding the summer months June, July and August as in these months the windows of the house were open for natural air circulation to maintain the air quality of the house. That is why the HRV was turned off for these months. So, the total HRV losses are found by the equation (3),

Total HRV losses $=$ HRV losses + electrical energy consumption

Here, we got the HRV losses $2508 \mathrm{kWh}$ from equation (1) for the whole year and electrical energy consumption of HRV $720 \mathrm{kWh}$ from equation (2) excluding the summer months. So, the total HRV loss $(2508+720)=3228 \mathrm{kWh}$ per year. That is a very significant heat loss. Cost of that will be about $(3228 * 0.15)=\$ 484$ per year.

\section{EXPERIMENTAL RESULTS AND DISCUSSION}

After logging the temperature difference data for one year, we calculated the energy loss as well as the power consumption of the HRV. After that, we analyzed these data through proper way and plotted using Microsoft Excel. Fig. 4. shows the monthly heat loss of the heat recovery unit. From the result, it can be said that the heat loss was high in winter because the need of heating load is comparatively higher in winter months than the summer months. The total yearly heat loss was found $2508 \mathrm{kWh}$ with highest value $402 \mathrm{kWh}$ in December.

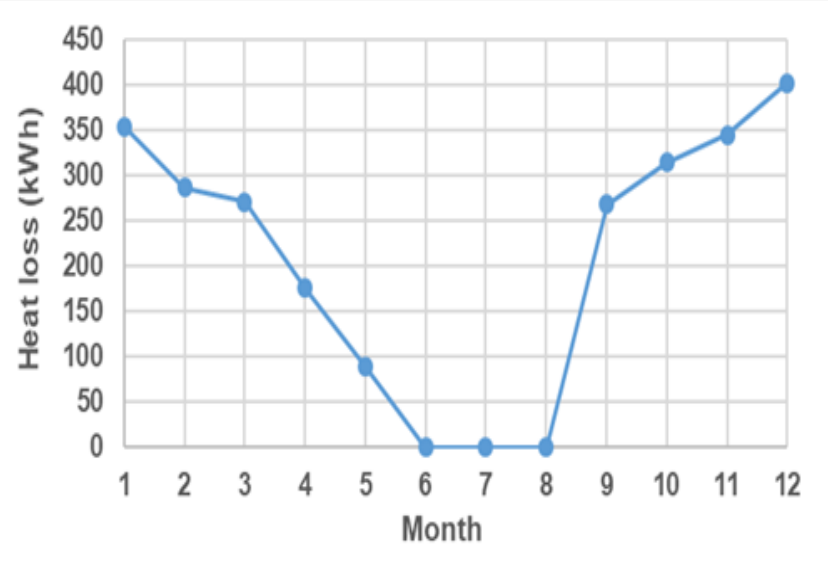

Fig. 4. Monthly HRV energy loss loss in summer is zero. As the temperature difference of incoming and exhaust air is high in extreme cold months, so the heat loss from HRV was high in those months. From the analysis, it is noticeable that the maximum value of heat loss was $1134 \mathrm{~W}$ in December, when it was very cold outside.

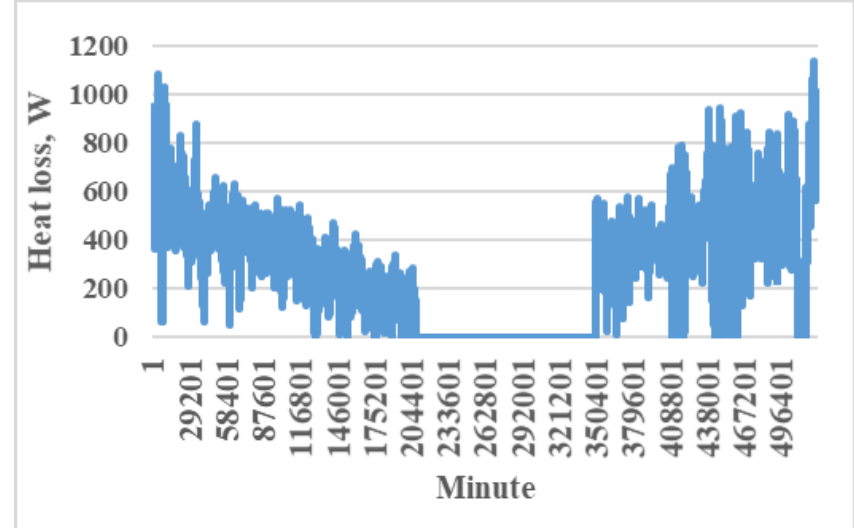

Fig. 5. Heat loss per minute from HRV

Fig. 6. offers the BE opt software analysis with heat recovery losses annually. Building Engineering Optimization (BE opt) is thermal modeling software that can be used to find out the different thermal loads of the selected house. For this software requirement, various house parameters with physical properties of the appliances are given as an input in this software. Among these loads, Mechanical ventilation unit (2010, HRV, 70\%), specified as a fraction of ASHRAE standard 62.2 is mentioned in this software. The result showed that the total amount of energy loss from this software is $700 \mathrm{kWh}$, but from the experimental result, the value was obtained $2508 \mathrm{kWh}$. Simulation error and the wrong selection of HRV properties are responsible for these discrepancies.

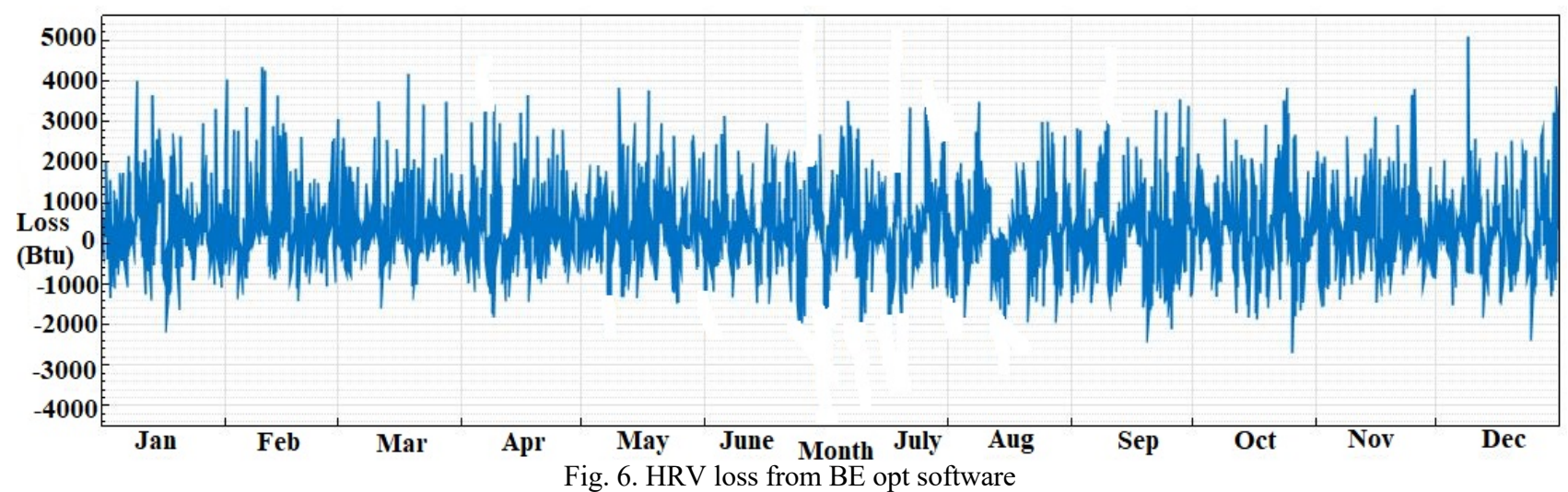

Fig. 5. demonstrates the heat loss per minute of the HRV throughout the whole year. The heat recovery unit was turned off in summer months. That is why the accumulated 
Relative humidity of the house from BE opt is shown by the fig. 7. As the thermal comfort and indoor air quality are the matter, we kept the controller knob in the comfort zone in winter and in the summer the knob was placed in summer mode. The relative humidity comfort zone range was (30-60) $\%$. In the user guide, it is mentioned that humidity level should not be selected below $30 \%$ to avoid the excessive dryness in the air. This dryness makes the discomfort for the occupants. From the fig. 7, it is concluded that the relative humidity is reached at the highest level at $70 \%$ in summer and maintained within the comfort zone during the winter. The result showed a good agreement with the literature.

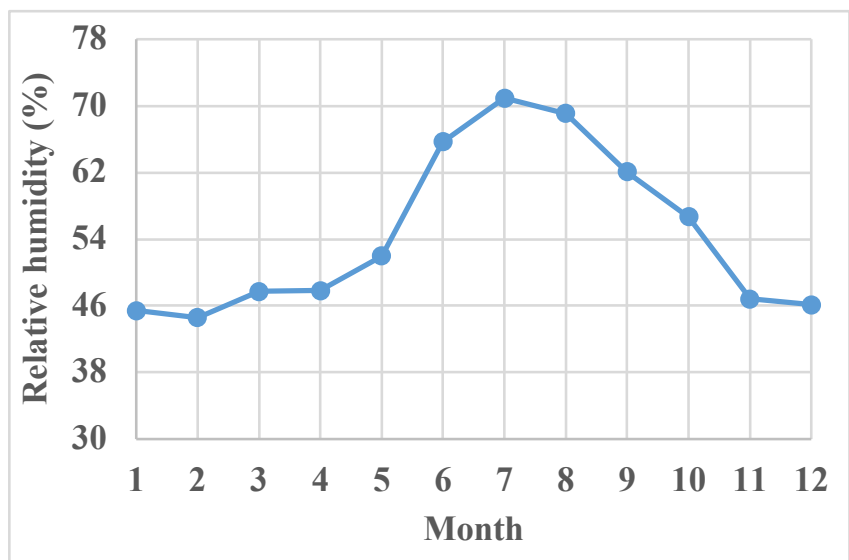

Fig. 7. Relative humidity of the house from BE opt software

\section{CONCLUSION}

In this research, yearly power consumption and heat loss analysis of a heat recovery ventilator were done experimentally in a cold climate area's house. Electrical energy consumption of the HRV was calculated $720 \mathrm{kWh}$ per year with constant running fan. A simple calculation approach is used to find out the heat loss of the HRV annually. The total amount of heat loss is obtained around $2508 \mathrm{kWh}$. As the heating energy demand is high in winter months, so the HRV loss followed the same trend with the highest heat loss amount $402 \mathrm{kWh}$ in December. Heat recovery ventilator is a useful part in order to make the house more energy-efficient, energy savings and proper utilization of energy. Though the system has enormous advantages in various sectors, especially in domestic buildings for their potential of saving energy and mitigating greenhouse gas emissions in the environment, it has certain amount of cost including power consumption as an input, maintenance and operation cost and the labor cost for making the condensation water vapor pan empty. In a nutshell, it can be said that a house with heat recovery ventilator enhanced indoor air quality but there is an associated cost that could be as high as $\$ 484$ per year.

\section{DATA AVAILABILITY}

The data used to support the findings of this study are available from the corresponding author upon request.

\section{CONFLICT OF INTEREST}

The authors of this work declare that all used software and devices were selected on research basis. Furthermore, the authors certify that there is no actual or potential conflict of interest in relation to this article.

\section{APPENDIX}

A. MATLAB Code

$\%$ MATLAB data acquisition toolbox example using USB- 1208LS

$\%$ Analog Input $\mathrm{CH} 0, \mathrm{CH} 1$, single ended mode. Range is $+/-10 \mathrm{~V}$

$\%$ amplifier gain 13.42 ; supply $5 \mathrm{~V}$, LM35 sensor $10 \mathrm{mV} / \mathrm{C}^{\prime}$

$\%$ Gain change is only possible in differential mode

daqhwinfo('mcc')

$\%$ read and review information. USB-1208LS is devic'0'

ai=analoginput ('mcc',0)

$\%$ add channels say 0 to 1 (all for inputs)

addchannel (ai, [0 1])

$\%$ Save date and time as a file name

name $=$ datestr (clock, 'yyyymmddTHHMMSS');

filename $=$ strcat (name, '.txt');

$\%$ datetime $=$ fix (clock);

fid=fopen (filename, 'wt.');

$\%$ fprintf (fid, '\%4.0f \%4.0f \%4.0f \%4.0f \%4.0f \%4.0f n', datetime);

$\%$ create file in current directory

$\%$ get 1000 samples per each channel at 1000

sample/second (default setting)

for $x=1: 43200$

start(ai)

$\%$ wait complete configuration

$\mathrm{X}$

$\%$ sampling time is $10 \mathrm{~s}$

pause (10)

rawdata=getdata(ai);

data $0=$ rawdata $(: 1)$;

datal=rawdata $(: 2)$;

$\mathrm{d} 0=$ mean $(\operatorname{data} 0)$;

$\mathrm{d} 1=$ mean (data1);

temp_in $=\mathrm{d} 0 / 13.42 / 0.01$

temp_out $=\mathrm{d} 1 / 13.42 / 0.01$

fprintf (fid,' $\% 6.4 \mathrm{f} \% 6.4 \mathrm{f} \backslash \mathrm{n}^{\prime}$, temp_in, temp_out);

end

fclose(fid);

$\%$ Cleanup workspace

delete(ai)

clear ai 


\section{ACKNOWLEDGMENT}

This research was funded by the Natural Sciences and Engineering Research Council (NSERC) of Canada. The authors would like to acknowledge the financial support of the NSERC and the technical support of friends, staff, and the Memorial University of Newfoundland.

\section{REFERENCES}

[1] A. Mardiana-Idayu and S. B. Riffat, "Review on heat recovery technologies for building applications," Renew. Sustain. Energy Rev., vol. 16, no. 2, pp. 1241-1255, Feb. 2012.

[2] İ. Teke, Ö. Ağra, Ş. Ö. Atayılmaz, and H. Demir, "Determining the best type of heat exchangers for heat recovery," Appl. Therm. Eng., vol. 30, no. 6-7, pp. 577-583, May 2010

[3] W. W. Nazaroff, M. L. Boegel, C. D. Hollowell, and G. D. Roseme, "The use of mechanical ventilation with heat recovery for controlling radon and radondaughter concentrations in houses," Atmospheric Environ. 1967, vol. 15, no. 3, pp. 263-270, Jan. 1981.

[4] H. Manz and H. Huber, "Experimental and numerical study of a duct/heat exchanger unit for building ventilation," Energy Build., vol. 32, no. 2, pp. 189-196, Jul. 2000.

[5] A. Nguyen, Y. Kim, and Y. Shin, "Experimental study of sensible heat recovery of heat pump during heating and ventilation," Int. J. Refrig., vol. 28, no. 2, pp. 242-252, Mar. 2005.

[6] S. B. Riffat and M. C. Gillott, "Performance of a novel mechanical ventilation heat recovery heat pump system," Appl. Therm. Eng., vol. 22, no. 7, pp. 839-845, May 2002.

[7] H. Manz, H. Huber, A. Schälin, A. Weber, M. Ferrazzini, and M. Studer, "Performance of single room ventilation units with recuperative or regenerative heat recovery," Energy Build., vol. 31 no. 1, pp. 37-47, Jan. 2000.

[8] J. Kragh, J. Rose, T. R. Nielsen, and S. Svendsen, "New counter flow heat exchanger designed for ventilation systems in cold climates," Energy Build., vol. 39, no. 11, pp. 1151-1158, Nov. 2007.

[9] P. M. Cuce and S. Riffat, "A comprehensive review of heat recovery systems for building applications," Renew. Sustain. Energy Rev., vol. 47, pp. 665-682, Jul. 2015.

[10] Y. Lu, Y. Wang, L. Zhu, and Q. Wang, "Enhanced performance of heat recovery ventilator by airflow-induced film vibration (HRV performance enhanced by FIV)," Int. J. Therm. Sci., vol. 49, no. 10 , pp. 2037-2041, Oct. 2010 .

[11] C. A. Hviid and S. Svendsen, "Analytical and experimental analysis of a low-pressure heat exchanger suitable for passive ventilation," Energy Build., vol. 43, no. 2-3, pp. 275-284, Feb. 2011.

[12] A. Persily, "Evaluation of an air-to-air heat exchanger," Environ. Int. vol. 8, no. 1-6, pp. 453-459, Jan. 1982

[13] K. Zhong and Y. Kang, "Applicability of air-to-air heat recovery ventilators in China," Appl. Therm. Eng., vol. 29, no. 5-6, pp. 830 840, Apr. 2009.

[14] H. Tommerup and S. Svendsen, "Energy savings in Danish residential building stock," Energy Build., vol. 38, no. 6, pp. 618626, Jun. 2006.

[15] S. C. Sugarman, HVAC Fundamentals, Third Edition, 3 editions. Lilburn, GA: Fairmont Press, 2015.

[16] "Heat Recovery Ventilation Guide for Multi-Unit Residentia Buildings." [Online]. Available: https://www.bchousing.org/researchcentre/library/residential-design-construction/heat-recoveryventilation-guide-murbs\&sortType=sortByDate. [Accessed: 14-Sep2019].

[17] "Heat Recovery Ventilator(HRV) vs Energy Recovery Ventilator(ERV): What's the Right Unit for Your Home?" EP Sales Inc., 21-Apr-2017.

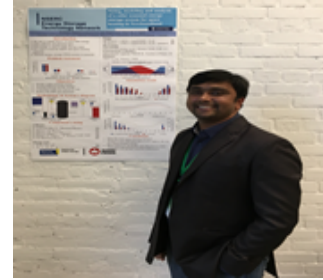

Rabbani Rasha was born in Kurigram, Bangladesh. He received his Bachelor of science in Mechanical Engineering (ME) degree from Department of Mechanical and Production Engineering of Ahsanullah University of Science and Technology (AUST), Dhaka, Bangladesh. After completing his degree in 2015, he started to work in a private company as an Assistant Mechanical Engineer. In winter 2018, he started his Masters degree at the Faculty of Engineering and Applied Science, Memorial university of Newfoundland, St. John's, NL, Canada. He received school of graduate studies (SGS) baseline and supervisor grant as a full scholarship. His main research area is Renewable Energy and currently he is focusing on to design, modelling and analysis of a small scale energy storage system for Newfoundland.

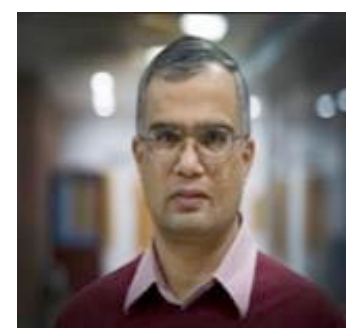

M. Tariq Iqbal received the B.S. (E.E.) degree from the University of Engineering and Technology, Lahore, Pakistan, in 1986, the M.S. degree in nuclear engineering from the Quaid-e-Azam University, Islamabad, Pakistan, in 1988, and the Ph.D. degree in electrical engineering from the Imperial College London, London, UK, in 1994. From 1988 to 1991 and again from 1995 to 1999 , he worked at the Pakistan Institute of Engineering and Applied Science, Islamabad, Pakistan. From 1999 to 2000, he worked as an Associate Professor at IIEC, Riphah International University, Islamabad, Pakistan. Since 2001, he has been working at the Faculty of Engineering and Applied Science, Memorial University of Newfoundland, St. John's, NL.

Presently, he is a Full Professor. His teaching activities cover a range of electrical engineering topics including electrical engineering design, control systems, renewable energy systems, and instrumentation. Currently, his research focuses on modeling and control of renewable energy systems with interests in the areas of design of control systems and comparison of control strategies of hybrid energy systems. 